\title{
Revisiting semicontinuous silver films as surface-enhanced Raman spectroscopy substrates
}

\author{
Malwina Liszewska ${ }^{1}$, Bogusław Budner ${ }^{1}$, Małgorzata Norek², Bartłomiej J. Jankiewicz ${ }^{1}$ \\ and Piotr Nyga*1
}

\author{
Full Research Paper \\ Address: \\ ${ }^{1}$ Institute of Optoelectronics, Military University of Technology, 2 gen. \\ Sylwestra Kaliskiego Street, 00-908 Warsaw, Poland and ${ }^{2}$ Faculty of \\ Advanced Technologies and Chemistry, Military University of \\ Technology, 2 gen. Sylwestra Kaliskiego Street, 00-908 Warsaw, \\ Poland \\ Email: \\ Piotr Nyga* - piotr.nyga@wat.edu.pl \\ * Corresponding author \\ Keywords: \\ metal island film; plasmon resonance; semicontinuous silver film; \\ SERS; surface-enhanced Raman spectroscopy
}

Beilstein J. Nanotechnol. 2019, 10, 1048-1055. doi:10.3762/bjnano.10.105

Received: 24 December 2018

Accepted: 05 May 2019

Published: 15 May 2019

This article is part of the thematic issue "Optically and electrically driven nanoantennas".

Guest Editor: A. J. Meixner

(C) 2019 Liszewska et al.; licensee Beilstein-Institut. License and terms: see end of document.

\begin{abstract}
Surface-enhanced Raman spectroscopy (SERS) is a very promising analytical technique for the detection and identification of trace amounts of analytes. Among the many substrates used in SERS of great interest are nanostructures fabricated using physical methods, such as semicontinuous metal films obtained via electron beam physical vapor deposition. In these studies, we investigate the influence of morphology of semicontinuous silver films on their SERS properties. The morphologies studied ranged from isolated particles through percolated films to almost continuous films. We found that films below the percolation threshold (transition from dielectric-like to metal-like) made of isolated silver structures provided the largest SERS enhancement of 4-aminothiophenol (4-ATP) analyte signals. The substrate closest to the percolation threshold has the SERS signal about four times lower than the highest signal sample.
\end{abstract}

\section{Introduction}

Noble metal nanostructures exhibit exceptional optical properties. They can efficiently absorb and/or scatter visible and near infrared electromagnetic radiation [1]. The origin of the above phenomena lies in localized surface plasmon resonances (LSPR). LSPRs are light induced oscillations of free electrons in metallic nanostructures. The spectral position of an LSPR depends on the dielectric constant of the metal, surrounding dielectric, shape and size of the nanostructure, and its orientation with respect to the electric component of the electromagnetic field [1,2]. At resonance, the electric field near the surface of metallic nanostructures can be greatly enhanced and localized in nanoscale regions called "hot spots" [3]. These "hot spots" can be utilized in surface-enhanced Raman spectroscopy (SERS) [4], allowing for the detection of trace amounts of 
chemicals and biological materials, down to the single molecule or cell level [5].

SERS was discovered in the 1970s [6-8] and a considerable amount of research has been devoted to this topic. However, there is still a need for further development of reproducible and inexpensive SERS substrates [9]. SERS substrates can be fabricated by a multitude of techniques. These techniques can be divided into chemical and physical methods. Chemical methods allow for fabrication, in solution or on surfaces, of nanostructures of various shapes including: nanospheres [5], spheres coated with a thin dielectric shell [10], dielectric core-metallic shell particles [11,12], nanostars [13], microflowers [14] and aggregates [15], just to mention a few examples. Gold and silver nanostructured surfaces on substrates can be fabricated by self-assembly of colloidal particles into monolayers [16], in the form of island films by seeding with nanoparticles followed by a reduction of metal salt $[17,18]$, or in the form of other high surface area structures $[19,20]$. Chemical fabrication methods are powerful in terms of the vast variety of attainable structure types, possible enhancement factors, and low cost of fabrication. However, reproducibility of SERS substrates can be an issue and the chemical compounds used for fabrication or stabilization of nanostructures can be a source of additional SERS signals [15], which may complicate SERS analysis with their use.

Various physical methods may be used to fabricate SERS substrates. Usually in these techniques silver or gold is deposited by physical vapor deposition (PVD) techniques. Nanostructures are obtained via various structuring methods. Electron beam lithography allows fabrication of planar [21] and 3D metallic structures [22]. Nanosphere lithography can be used to obtain nanotriangles [23] and nanocones [24]. Much attention has been also given to the deposition of metal onto nano- and microstructured surfaces made of glass [25,26], GaN [27-29], Si [30], $\mathrm{TiO}_{2}$ [31], $\mathrm{Al}_{2} \mathrm{O}_{3}$ [32], Ti [33], polymers [34], or planar surfaces coated with nano/microspheres resulting in metal film on nanospheres MFON [35,36], and Au nanocrescents on a monolayer of polystyrene nanospheres [37]. Additionally glancingangle deposition (GLAD) has been explored for the fabrication of vertical nanorods on planar substrates [38].

A special class of nanostructured surfaces are semicontinuous silver films (SSFs) $[39,40]$ also known as metal island films [41], which are comprised of random fractal-type structures. SSFs can be fabricated on large area planar substrates using electron beam (or thermal) PVD techniques, and thus are simple to prepare and rather inexpensive. Island type structures can be also fabricated using pulsed laser deposition [42]. The SSFs form when 5-10 nm (mass thickness corresponding to hypothet- ical continuous film) of silver is e-beam deposited on a proper adhesion layer (for example silicon dioxide) $[43,44]$. The results of simulations and experimental studies show that the hot spots exist in SSFs [2,44-47], and hence they have been extensively studied as SERS substrates [40,41,48-55]. However, transmittance, reflectance and absorption are rarely reported in these studies, and it is difficult to link the optical properties of these nanostructures with their SERS performance. In our earlier initial study we investigated SSFs as SERS substrates [55], however the set of samples was limited to only four (with mass thickness from $3 \mathrm{~nm}$ to $10 \mathrm{~nm}$ ) and they were characterized with a limited number of techniques.

The aim of this work is to revisit SSFs for their applications in SERS and perform a systematic study allowing for the correlation of the optical properties of silver film structures, with their SERS properties. We have investigated SERS enhancement of 4-aminothiophenol on nine SSFs with metal structures ranging from isolated particles, through percolated, to almost continuous film. We found that the largest SERS enhancement is observed for SSFs below the percolation threshold. The sample closest to the threshold has a SERS signal about four times lower than for the highest signal case.

\section{Experimental Materials}

Silver deposition material (99.99\%) and BK7 glass substrates were purchased from Umicore. For glass substrates cleaning process, we used sulfuric acid (97\%; Fluka), hydrogen peroxide (30\%; Chempur), ethanol ( $96 \%$; Chempur) and deionized water. SERS analyte 4-aminothiophenol (97\%) was purchased from Sigma-Aldrich.

\section{Fabrication of semicontinuous silver films}

SSFs were fabricated on BK7 glass substrates using the electron beam PVD technique. The substrates were first cleaned with piranha solution $\left(\mathrm{H}_{2} \mathrm{SO}_{4} / \mathrm{H}_{2} \mathrm{O}_{2} 3: 1\right)$ for 30 minutes, then rinsed with deionized water, followed by multiple rinses with ethanol. The substrates were then placed in an electron beam vacuum evaporation chamber. The base pressure of the chamber was about $2 \times 10^{-6}$ mbar. Deposition was performed at room temperature. Glass substrates were first coated with $10 \mathrm{~nm}$ thick layer of silicon dioxide $\left(\mathrm{SiO}_{2}\right)$. Next, without breaking vacuum, silver was deposited on the substrates. Two depositions were performed and in each of them several substrates were located at a different distance from the evaporation source to fabricate films with different thicknesses. In such way in two depositions a total of nine samples were fabricated. In order to ensure uniform thickness of $\mathrm{SiO}_{2}$, the substrates were rotated during the deposition process. The thickness of deposited films was monitored with quartz crystal microbalance. 


\section{Characterization of semicontinuous silver films}

Optical properties of SSFs were characterized using UV-vis-NIR Perkin Elmer Lambda 900 spectrometer. Transmittance was measured using a standard detector, while reflectance was measured with an integrating sphere module. Absorption was calculated assuming the sum of transmittance, reflectance, and absorption is $100 \%$. The morphology of the fabricated structures was measured using a Quanta 3D FEG Dual Beam scanning electron microscope (SEM) and an atomic force microscope (AFM). The SEM images of SSFs were converted to black and white and metal coverage was calculated. The AFM maps were collected using an NTEGRA atomic force microscope from NT-MDT company. The surface topography measurements were made in semi-contact mode. We used HA_NC ETALON (NT-MDT) probe with $140 \mathrm{kHz} \pm 10 \%$ resonant frequency, force constant of $3.5 \mathrm{~N} / \mathrm{m} \pm 20 \%$ and standard tip curvature radius less than $10 \mathrm{~nm}$. The thickness of SSFs was measured on the edge (step) formed through removing of a part of the silver film from the substrate (using a blade).

\section{SERS measurements}

The 4-aminothiophenol was used as a SERS analyte. In order to form a monolayer of 4-ATP on the silver nanostructures we immersed the SSF substrates into $10 \mathrm{mM}$ ethanol solution of 4-ATP for 1 hour. Longer incubation times did not result in SERS signal increase. The excess 4-ATP molecules were removed by rinsing the SSF samples with ethanol. The solvent was allowed to evaporate slowly.

The SERS measurements of 4-ATP analyte on SSFs samples were carried out using a Renishaw inVia Raman microscope. The Raman signal was acquired in the spectral range of $250-2000 \mathrm{~cm}^{-1}$ using laser radiation with a wavelength of $785 \mathrm{~nm}$. The laser excitation power was $75 \mu \mathrm{W}$ on the sample. The laser beam was directed to the sample through a $50 \times$ (N.A. $=0.75$ ) objective lens. We used a 10 second integration time. On each SSF sample we measured the Raman signal in three locations and averaged. The wavelength of the instrument was calibrated using an internal silicon wafer, the spectrum was centered at $520.5 \mathrm{~cm}^{-1}$.

\section{Results and Discussion}

We fabricated a series of nine (named A-I) SSF samples with different silver thickness (Figure 1 and Figure 2). The SSFs were prepared on glass substrates using electron-beam PVD (see Experimental section for details). We used transparent substrates in order to be able to measure transmittance and reflectance. We performed two depositions. Each deposition was concurrently performed on several substrates located at different distances from the evaporation source to get different silver film thicknesses. In such way in two depositions a total of nine SSF samples with different film thicknesses were fabricated. SEM images of the A-I SSFs are presented in Figure 1. They are arranged in a way that metal coverage (presented in Table 1) increases from A to I. Changes of the metal film thicknesses resulted in different SSFs morphologies. Sample A is comprised of small isolated particles. As the thickness increases the nanoparticles grow and their total number (per surface area) decreases (samples B-D). Next, the particles connect forming irregular fractal type shapes (samples E, F). As the amount of deposited metal further increases the metal coverage increases and the film reaches the percolation threshold - the transition from dielectric-like to metal-like (sample $\mathrm{G}$ is already above percolation threshold), where a metallic path forms across the sample. Finally, silver covers almost the entire surface of the substrate (sample I). The percolation point can be deducted from SEM images. One has to determine silver coverage or thickness for which a Ag path across the image/sample is formed. This can be performed through for example image analysis techniques. In the set of our nine samples we do not have a sample "at percolation". The percolation would happen for a hypothetical sample between sample F and G (as for sample F we do not observe continuous silver path and for sample $G$ several paths across the SEM image exist).

In order to determine the physical thickness of the SSFs we carried out AFM studies (data presented in Table 1). For each of the SSFs a part of the silver film was removed to form a step like structure with two distinct areas (glass with silicon dioxide and glass with silicon dioxide and silver film) of different height. A several micrometer square AFM scan (not presented) of such step-like structures provides an estimate of the SSF height but does not show the fine structure of the SSF. In order to visualize the height and morphology of silver nanostructures we performed AFM scans of relatively small areas of SSFs (Figure 2). The AFM data in Figure 2 corresponds well with the SEM images presented in Figure 1. The size of particles increases for samples from A to I. Also, the measured height range increases.

The morphologies of SSFs strongly influence their optical properties. The measured transmittance, reflectance, and absorption of fabricated SSFs are presented in Figure 3. Film A has an absorption peak centered at about $435 \mathrm{~nm}$. This peak corresponds to LSPR of isolated silver nanoparticles. With increased silver coverage the absorption peak broadens and shifts to longer wavelengths (samples B-E). Sample F has almost wavelength independent absorption (as well as transmittance and reflectance). Such behavior is known for metal films close to percolation [56]. This is because almost percolated films are comprised of nanostructures with different particle sizes and 

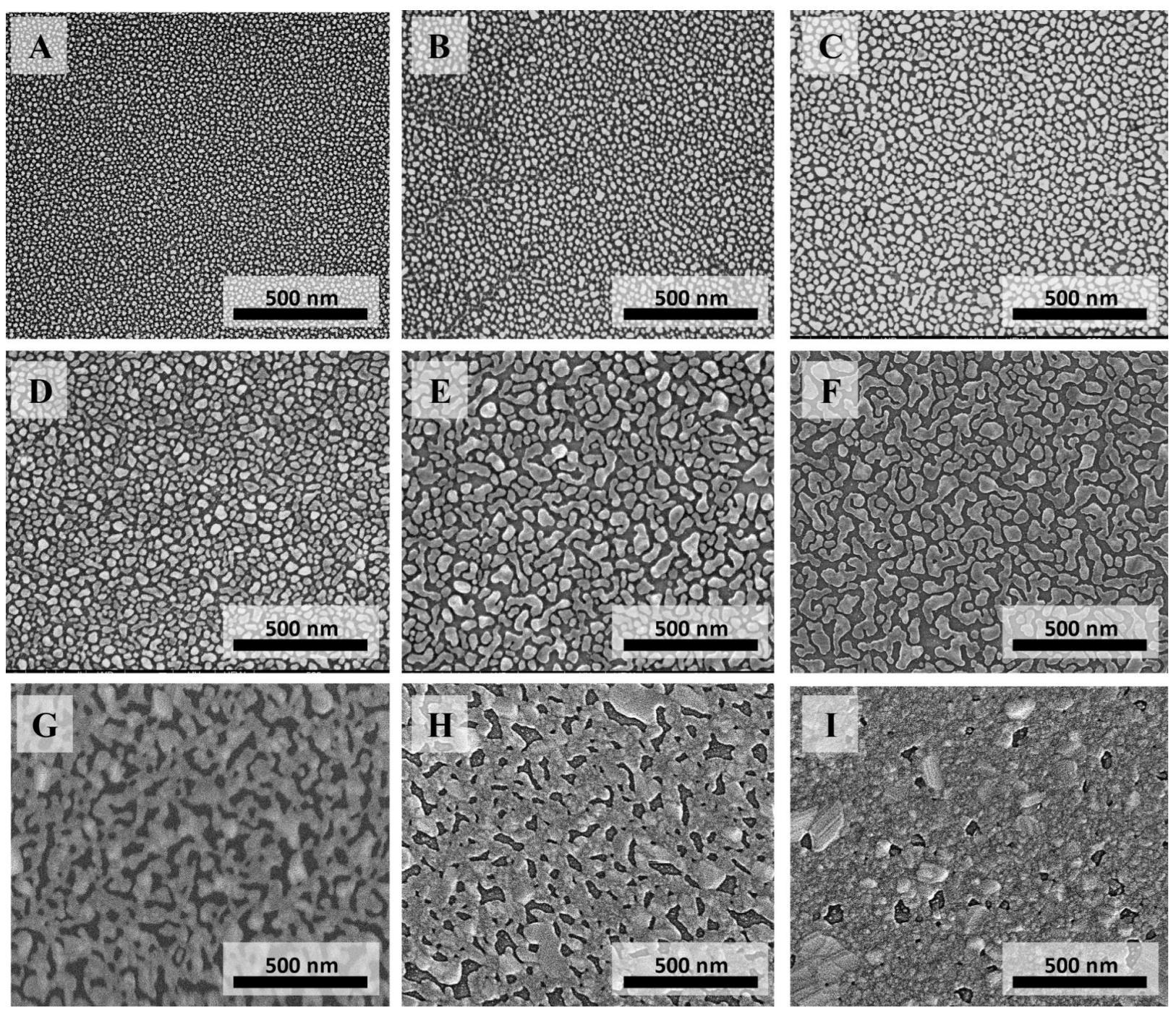

Figure 1: (A-I) SEM images of SSFs with different Ag thickness.

shapes, which results in absorption of electromagnetic energy across a broad wavelength range extending from the visible to the far infrared. For samples above percolation G-I reflectance increases (as the film is more metallic) and both absorption and transmittance decrease.

SERS properties of fabricated SSFs were examined using 4-ATP. We used $785 \mathrm{~nm}$ excitation wavelength. The 4-ATP SERS spectra measured on all SSFs are presented in Figure 4. In the spectra there are three prominent peaks at 389, 1080 and $1595 \mathrm{~cm}^{-1}$. The first two can be assigned to the $\mathrm{C}-\mathrm{S}$ stretching mode and the third to $\mathrm{C}-\mathrm{C}$ stretching mode. Four relatively weak peaks at $1180,1392,1437$ and $1490 \mathrm{~cm}^{-1}$ can be assigned to the same $\mathrm{C}-\mathrm{H}$ bending and a combination of $\mathrm{C}-\mathrm{C}$ stretching and $\mathrm{C}-\mathrm{H}$ bending. The characteristic peaks observed in 4-ATP spectra are in agreement with peaks reported in the literature [57].
At the excitation wavelength of $785 \mathrm{~nm}$ the SSFs have different absorption (Figure 3), from $0 \%$ for sample A, increasing to about $34 \%$ for sample $\mathrm{F}$ and decreasing to $11 \%$ for sample I (Figure 3). Despite low absorption at the excitation wavelength, a weak SERS signal was detected on sample A. This is in an agreement with previous reports of good quality SERS spectra obtained on substrates with a LSPR far away from the excitation laser wavelength [58]. We did not observe SERS signal for the sample I with the highest metal coverage. The highest SERS signal was obtained for samples C, D and E. These samples have different absorption at excitation wavelength, but they have similar morphology. These three samples are below percolation (SEM images in Figure 1) and have similar metal coverage (0.51-0.55; Table 1). Since each of the nine SSF samples has a different metal coverage there is a different surface area available for 4-ATP binding, thus different number of molecules per unit area. In order to exclude this effect, we normal- 

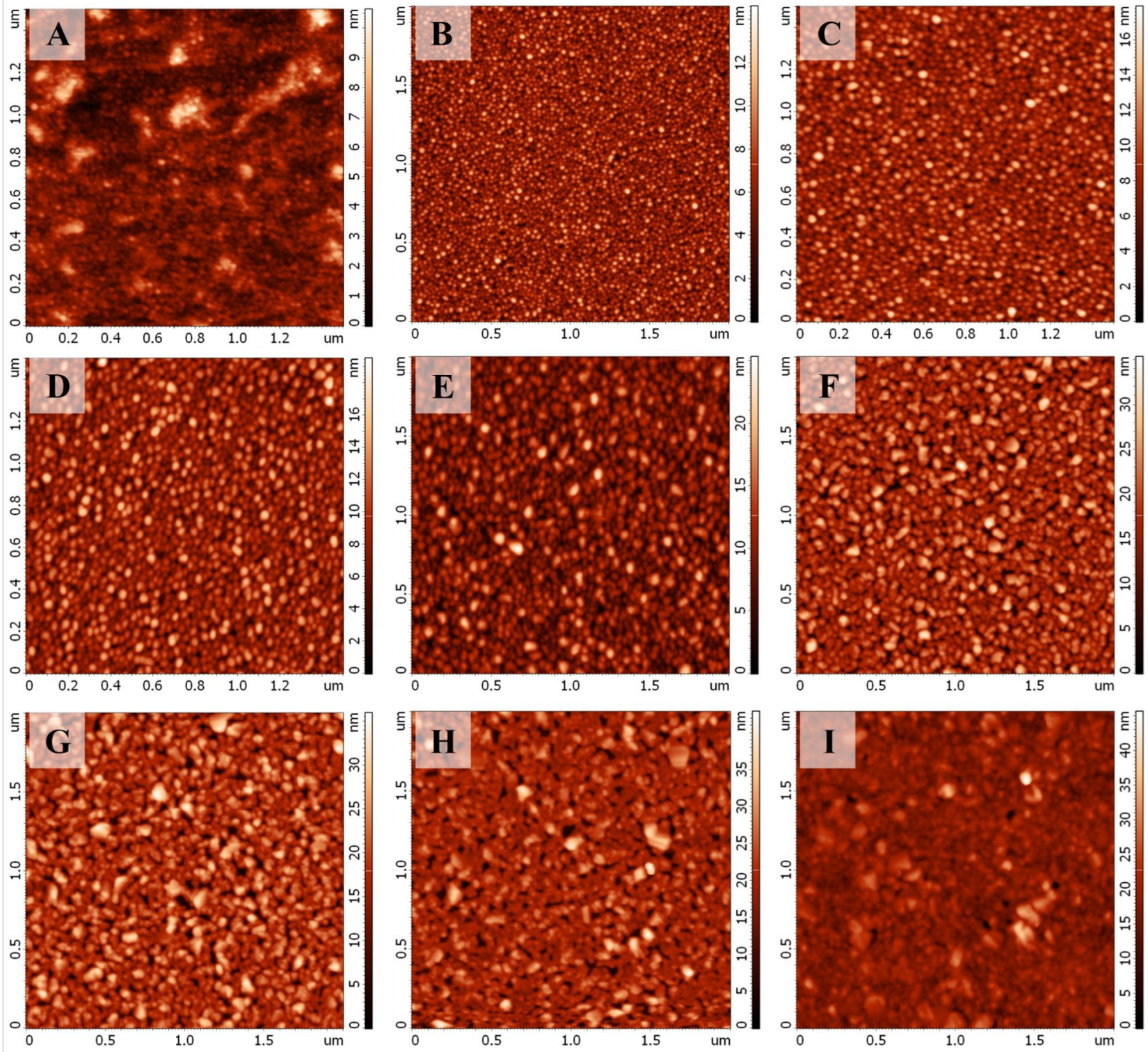

Figure 2: (A- I) AFM maps of SSFs with different Ag thickness. Samples A, C and D have a different scan area than the other samples.

Table 1: The AFM-determined thicknesses of semicontinuous Ag films and estimated values of metal filling factors.

\begin{tabular}{lll} 
Sample & $\begin{array}{l}\text { AFM-determined } \\
\text { Ag thickness [nm] }\end{array}$ & Ag filling factor \\
\hline A & 8.75 & $0.428 \pm 0.029$ \\
B & 13.24 & $0.430 \pm 0.022$ \\
C & 13.37 & $0.513 \pm 0.012$ \\
D & 12.27 & $0.522 \pm 0.001$ \\
E & 20.46 & $0.549 \pm 0.009$ \\
F & 24.51 & $0.572 \pm 0.008$ \\
G & 23.88 & $0.641 \pm 0.024$ \\
H & 25.42 & $0.768 \pm 0.021$ \\
I & 22.35 & $0.937 \pm 0.009$
\end{tabular}

ized the measured SERS signals by the metal coverage (presented in Table 1). The measured and metal coverage corrected signals of the $1080 \mathrm{~cm}^{-1}$ peak for A-I SSFs are presented in Figure 5. For both measured and normalized case the samples $\mathrm{C}-\mathrm{E}$ show high SERS signal with the D sample having the highest signal. The 4-ATP SERS signal recorded on SSFs above percolation (samples $\mathrm{G}$ and $\mathrm{H}$ ) was at least an order of magnitude lower than that for the case of the three samples with highest SERS signal. For the case of SSFs fabricated using our protocol it is possible to determine if the film is below percolation from the transmittance and/or reflectance measurements (transmittance increases, reflectance decreases for wavelengths in the range of about one micrometer) without the need for expensive and time-consuming structural characterization. 

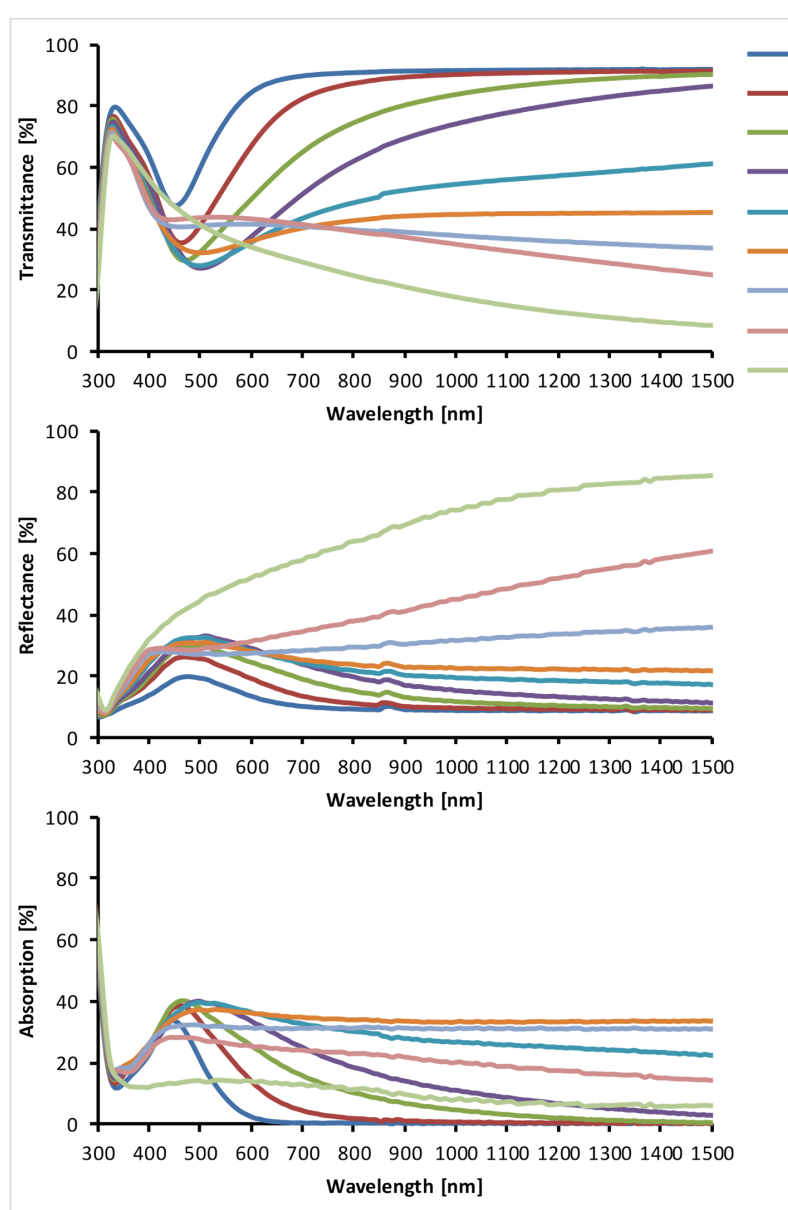

Figure 3: Transmittance, reflectance and absorption spectra of A- I SSF films.

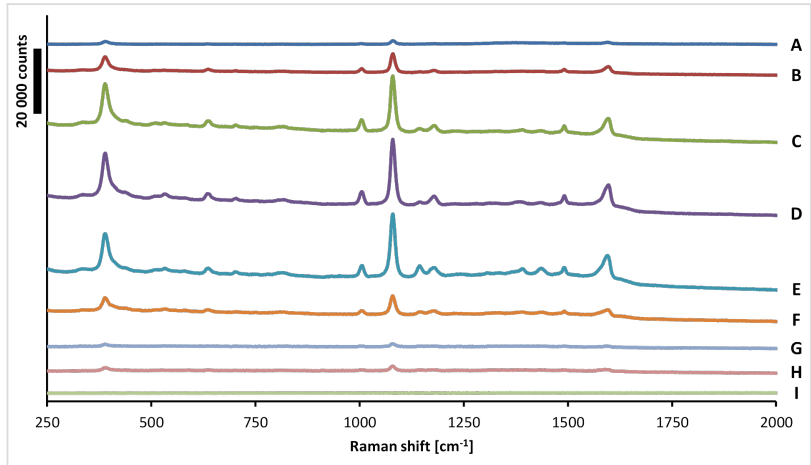

Figure 4: SERS spectra of 4-ATP molecules on A-I SSFs.

This could be used as a quick method for initial optimization of SSF thickness for high SERS signal.

Calculation of the SERS enhancement factor of a SERS substrate is extremely difficult since a proper reference sample is needed and there is an ongoing debate in the community regarding the appropriate procedures [59]. We decided to estimate the lower limit of the enhancement factor by adopting an

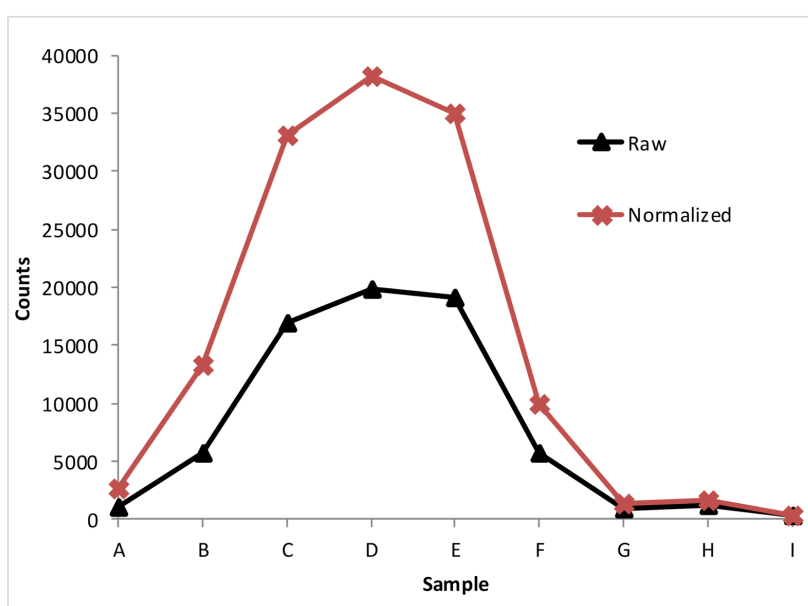

Figure 5: SERS signal of $1080 \mathrm{~cm}^{-1}$ band measured on SSFs A-I (Raw) and normalized by their metal coverage (Normalized).

approach similar to one used in the reference [20]. We compared the metal coverage normalized SERS signal of the D sample with the signal of the almost continuous I sample. As no SERS signal was observed on the sample I, we assumed that the upper limit of the signal is the peak-to-peak noise measurement [20]. By dividing the silver coverage corrected signal of the Raman band at $1080 \mathrm{~cm}^{-1}$ by the peak-to-peak noise of the measurement on the sample I we obtained a lower limit of the enhancement factor of about 630 .

\section{Conclusion}

We have fabricated semicontinuous silver films with various morphologies, ranging from isolated particles, through percolated to almost continuous film, and investigated their performance as SERS substrates. The SERS activity of studied substrates was explained with relation to their morphologies and optical properties. SERS tests using 4-ATP as an analyte confirmed that the Raman signal enhancement is strongly dependent on the morphology and optical properties of the substrate, and particularly absorption of the film. We found that films below the percolation threshold, composed of isolated silver structures, provide the highest SERS signal. For the sample closest to the percolation threshold the SERS signal is about four times lower than in the highest signal case. The semicontinuous silver films above percolation threshold produced 4-ATP SERS signal at least an order of magnitude lower than the best film.

\section{Acknowledgements}

This research was supported by the LIDER/23/22/L-3/11/ NCBR/2012 grant funded by the Polish National Centre for Research and Development. This work was performed in the frame of the European Cooperation in Science and Technology COST Action MP1302 Nanospectroscopy. 


\section{ORCID ${ }^{\circledR}$ iDs}

Malwina Liszewska - https://orcid.org/0000-0001-5102-641X Bogusław Budner - https://orcid.org/0000-0002-9395-6073 Małgorzata Norek - https://orcid.org/0000-0002-0460-486X Bartłomiej J. Jankiewicz - https://orcid.org/0000-0002-1172-8764 Piotr Nyga - https://orcid.org/0000-0002-7591-7142

\section{References}

1. Bohren, C. F.; Huffman, D. R., Eds. Absorption and Scattering of Light by Small Particles; Wiley-VCH Verlag GmbH: Weinheim, Germany, 1983. doi:10.1002/9783527618156

2. Aroca, R.; Martin, F. J. Raman Spectrosc. 1985, 16, 156-162. doi:10.1002/jrs.1250160305

3. Markel, V. A.; Shalaev, V. M.; Zhang, P.; Huynh, W.; Tay, L.; Haslett, T. L.; Moskovits, M. Phys. Rev. B 1999, 59, 10903-10909. doi:10.1103/physrevb.59.10903

4. Moskovits, M. Rev. Mod. Phys. 1985, 57, 783-826. doi:10.1103/revmodphys.57.783

5. Kneipp, K.; Wang, Y.; Kneipp, H.; Perelman, L. T.; Itzkan, I.; Dasari, R. R.; Feld, M. S. Phys. Rev. Lett. 1997, 78, 1667-1670. doi:10.1103/physrevlett.78.1667

6. Fleischmann, M.; Hendra, P. J.; McQuillan, A. J. Chem. Phys. Lett. 1974, 26, 163-166. doi:10.1016/0009-2614(74)85388-1

7. Albrecht, M. G.; Creighton, J. A. J. Am. Chem. Soc. 1977, 99, 5215-5217. doi:10.1021/ja00457a071

8. Jeanmaire, D. L.; Van Duyne, R. P. J. Electroanal. Chem. Interfacial Electrochem. 1977, 84, 1-20. doi:10.1016/s0022-0728(77)80224-6

9. Liszewska, M.; Bartosewicz, B.; Budner, B.; Nasiłowska, B.; Szala, M.; Weyher, J. L.; Dzięcielewski, I.; Mierczyk, Z.; Jankiewicz, B. J. Vib. Spectrosc. 2019, 100, 79-85. doi:10.1016/j.vibspec.2018.11.002

10. Li, J. F.; Huang, Y. F.; Ding, Y.; Yang, Z. L.; Li, S. B.; Zhou, X. S.; Fan, F. R.; Zhang, W.; Zhou, Z. Y.; Wu, D. Y.; Ren, B.; Wang, Z. L.; Tian, Z. Q. Nature 2010, 464, 392-395. doi:10.1038/nature08907

11. Jackson, J. B.; Halas, N. J. Proc. Natl. Acad. Sci. U. S. A. 2004, 101, 17930-17935. doi:10.1073/pnas.0408319102

12. Talley, C. E.; Jackson, J. B.; Oubre, C.; Grady, N. K.; Hollars, C. W.; Lane, S. M.; Huser, T. R.; Nordlander, P.; Halas, N. J. Nano Lett. 2005 5, 1569-1574. doi:10.1021/nl050928v

13. Rodríguez-Lorenzo, L.; Álvarez-Puebla, R. A.; de Abajo, F. J. G.; Liz-Marzán, L. M. J. Phys. Chem. C 2010, 114, 7336-7340. doi:10.1021/jp909253w

14. Winkler, K.; Kaminska, A.; Wojciechowski, T.; Holyst, R.; Fialkowski, M Plasmonics 2011, 6, 697-704. doi:10.1007/s11468-011-9253-0

15. Yaffe, N. R.; Blanch, E. W. Vib. Spectrosc. 2008, 48, 196-201. doi:10.1016/j.vibspec.2007.12.002

16. Freeman, R. G.; Grabar, K. C.; Allison, K. J.; Bright, R. M.; Davis, J. A.; Guthrie, A. P.; Hommer, M. B.; Jackson, M. A.; Smith, P. C.; Walter, D. G.; Natan, M. J. Science 1995, 267, 1629-1632. doi:10.1126/science.267.5204.1629

17. Khlebtsov, B. N.; Khanadeev, V. A.; Panfilova, E. V.; Bratashov, D. N.; Khlebtsov, N. G. ACS Appl. Mater. Interfaces 2015, 7, 6518-6529. doi:10.1021/acsami.5b01652

18. Bartosewicz, B.; Gajda-Raczka, M.; Jankiewicz, B. J. Photonics Lett. Pol. 2013, 5, 48-50. doi:10.4302/plp.2013.2.05

19. Schneidewind, H.; Schüler, T.; Strelau, K. K.; Weber, K.; Cialla, D.; Diegel, M.; Mattheis, R.; Berger, A.; Möller, R.; Popp, J. Beilstein J. Nanotechnol. 2012, 3, 404-414. doi:10.3762/bjnano.3.47
20. Gürdal, E.; Dickreuter, S.; Noureddine, F.; Bieschke, P.; Kern, D. P.; Fleischer, M. Beilstein J. Nanotechnol. 2018, 9, 1977-1985. doi:10.3762/bjnano.9.188

21. Banaee, M. G.; Crozier, K. B. Opt. Lett. 2010, 35, 760-762. doi:10.1364/ol.35.000760

22. Xiao, X.; Nogan, J.; Beechem, T.; Montano, G. A.; Washburn, C. M.; Wang, J.; Brozik, S. M.; Wheeler, D. R.; Burckel, D. B.; Polsky, R. Chem. Commun. 2011, 47, 9858-9860. doi:10.1039/c1cc12072g

23. Haynes, C. L.; Van Duyne, R. P. J. Phys. Chem. B 2003, 107 7426-7433. doi:10.1021/jp027749b

24. Horrer, A.; Schäfer, C.; Broch, K.; Gollmer, D. A.; Rogalski, J.; Fulmes, J.; Zhang, D.; Meixner, A. J.; Schreiber, F.; Kern, D. P.; Fleischer, M. Small 2013, 9, 3987-3992. doi:10.1002/smll.201300449

25. Liao, P. F.; Bergman, J. G.; Chemla, D. S.; Wokaun, A.; Melngailis, J.; Hawryluk, A. M.; Economou, N. P. Chem. Phys. Lett. 1981, 82, 355-359. doi:10.1016/0009-2614(81)85172-x

26. Oh, Y.-J.; Jeong, K.-H. Adv. Mater. (Weinheim, Ger.) 2012, 24, 2234-2237. doi:10.1002/adma 201104696

27. Kamińska, A.; Dzięcielewski, I.; Weyher, J. L.; Waluk, J.; Gawinkowski, S.; Sashuk, V.; Fiałkowski, M.; Sawicka, M.; Suski, T.; Porowski, S.; Hołyst, R. J. Mater. Chem. 2011, 21, 8662-8669. doi:10.1039/c0jm03336g

28. Weyher, J. L.; Bartosewicz, B.; Dzięcielewski, I.; Krajczewski, J.; Jankiewicz, B.; Nowak, G.; Kudelski, A. Appl. Surf. Sci. 2019, 466, 554-561. doi:10.1016/j.apsusc.2018.10.076

29. Bartosewicz, B.; Andersson, P. O.; Dzięcielewski, I.; Jankiewicz, B.; Weyher, J. L. Mater. Sci. Semicond. Process. 2019, 91, 97-101. doi:10.1016/j.mssp.2018.11.012

30. Perney, N. M. B.; Baumberg, J. J.; Zoorob, M. E.; Charlton, M. D. B.; Mahnkopf, S.; Netti, C. M. Opt. Express 2006, 14, 847-857. doi:10.1364/opex.14.000847

31. Roguska, A.; Kudelski, A.; Pisarek, M.; Lewandowska, M.; Dolata, M.; Janik-Czachor, M. J. Raman Spectrosc. 2009, 40, 1652-1656. doi:10.1002/jrs.2314

32. Malek, K.; Brzózka, A.; Rygula, A.; Sulka, G. D. J. Raman Spectrosc 2014, 45, 281-291. doi:10.1002/jrs.4452

33. Grochowska, K.; Siuzdak, K.; Sokołowski, M.; Karczewski, J.; Szkoda, M.; Śliwiński, G. Appl. Surf. Sci. 2016, 388, 716-722. doi:10.1016/j.apsusc.2016.01.186

34. Repetto, D.; Giordano, M. C.; Foti, A.; Gucciardi, P. G.; Mennucci, C.; Buatier de Mongeot, F. Appl. Surf. Sci. 2018, 446, 83-91. doi:10.1016/j.apsusc.2018.02.163

35. Goudonnet, J. P.; Begun, G. M.; Arakawa, E. T. Chem. Phys. Lett. 1982, 92, 197-201. doi:10.1016/0009-2614(82)80105-x

36. Dick, L. A.; McFarland, A. D.; Haynes, C. L.; Van Duyne, R. P. J. Phys. Chem. B 2002, 106, 853-860. doi:10.1021/jp013638I

37. Giordano, M. C.; Foti, A.; Messina, E.; Gucciardi, P. G.; Comoretto, D.; Buatier de Mongeot, F. ACS Appl. Mater. Interfaces 2016, 8, 6629-6638. doi:10.1021/acsami.5b11843

38. Chaney, S. B.; Shanmukh, S.; Dluhy, R. A.; Zhao, Y.-P. Appl. Phys. Lett. 2005, 87, 031908. doi:10.1063/1.1988980

39. Ducourtieux, S.; Podolskiy, V. A.; Grésillon, S.; Buil, S.; Berini, B.; Gadenne, P.; Boccara, A. C.; Rivoal, J. C.; Bragg, W. D.; Banerjee, K.; Safonov, V. P.; Drachev, V. P.; Ying, Z. C.; Sarychev, A. K.; Shalaev, V. M. Phys. Rev. B 2001, 64, 165403. doi:10.1103/physrevb.64.165403

40. Drachev, V. P.; Thoreson, M.; Khaliullin, E. N.; Sarychev, A. K.; Zhang, D.; Ben-Amotz, D.; Shalaev, V. M. Proc. SPIE 2003, 5221, 76. doi:10.1117/12.510572 
41. Schlegel, V. L.; Cotton, T. M. Anal. Chem. (Washington, DC, U. S.) 1991, 63, 241-247. doi:10.1021/ac00003a010

42. Budner, B.; Kuźma, M.; Nasiłowska, B.; Bartosewicz, B.; Liszewska, M.; Jankiewicz, B. J. Beilstein J. Nanotechnol. 2019, 10, 882-893. doi:10.3762/bjnano.10.89

43. Nyga, P.; Drachev, V. P.; Thoreson, M. D.; Shalaev, V. M. Appl. Phys. B: Lasers Opt. 2008, 93, 59-68. doi:10.1007/s00340-008-3145-9

44. Chettiar, U. K.; Nyga, P.; Thoreson, M. D.; Kildishev, A. V.; Drachev, V. P.; Shalaev, V. M. Appl. Phys. B: Lasers Opt. 2010, 100, 159-168. doi:10.1007/s00340-010-3985-y

45. Brouers, F.; Sarychev, A. K.; Blacher, S.; Lothaire, O. Phys. A (Amsterdam, Neth.) 1997, 241, 146-153. doi:10.1016/s0378-4371(97)00074-5

46. Grésillon, S.; Aigouy, L.; Boccara, A. C.; Rivoal, J. C.; Quelin, X.; Desmarest, C.; Gadenne, P.; Shubin, V. A.; Sarychev, A. K.; Shalaev, V. M. Phys. Rev. Lett. 1999, 82, 4520-4523. doi:10.1103/physrevlett.82.4520

47. Pavaskar, P.; Hsu, I.-K.; Theiss, J.; Hsuan Hung, W.; Cronin, S. B. J. Appl. Phys. 2013, 113, 034302. doi:10.1063/1.4775784

48. Gadenne, P.; Gagnot, D.; Masson, M. Phys. A (Amsterdam, Neth.) 1997, 241, 161-165. doi:10.1016/s0378-4371(97)00076-9

49. Oates, T. W. H.; Noda, S. Appl. Phys. Lett. 2009, 94, 053106. doi:10.1063/1.3078272

50. Oates, T. W. H.; Sugime, H.; Noda, S. J. Phys. Chem. C 2009, 113, 4820-4828. doi:10.1021/jp8097654

51. Drachev, V. P.; Thoreson, M. D.; Khaliullin, E. N.; Davisson, V. J.; Shalaev, V. M. J. Phys. Chem. B 2004, 108, 18046-18052. doi:10.1021/jp047254h

52. Drachev, V. P.; Nashine, V. C.; Thoreson, M. D.; Ben-Amotz, D.; Davisson, V. J.; Shalaev, V. M. Langmuir 2005, 21, 8368-8373. doi:10.1021/la0502490

53. Perumal, J.; Kong, K. V.; Dinish, U. S.; Bakker, R. M.; Olivo, M. RSC Adv. 2014, 4, 12995-13000. doi:10.1039/c3ra44867c

54. Šubr, M.; Kuzminova, A.; Kylián, O.; Procházka, M. Spectrochim. Acta, Part A 2018, 197, 202-207. doi:10.1016/j.saa.2018.01.055

55. Liszewska, M.; Stefaniak, M.; Firak, J.; Bartosewicz, B.; Budner, B.; Wojciechowski, T.; Jankiewicz, B. J.; Nyga, P. Influence of silver thickness on optical properties of metal island films fabricated by physical vapour deposition. 16th International Conference on Transparent Optical Networks (ICTON), Graz, Austria, July 6-10, 2014; 2014; pp 1-3. doi:10.1109/icton.2014.6876658

56. Gadenne, P.; Beghdadi, A.; Lafait, J. Opt. Commun. 1988, 65, 17-21. doi:10.1016/0030-4018(88)90433-6

57. Liu, Y.; Zhang, Y.; Ding, H.; Xu, S.; Li, M.; Kong, F.; Luo, Y.; Li, G. J. Mater. Chem. A 2013, 1, 3362-3371. doi:10.1039/c3ta00953j

58. Álvarez-Puebla, R. A. J. Phys. Chem. Lett. 2012, 3, 857-866. doi:10.1021/jz201625j

59. Le Ru, E. C.; Blackie, E.; Meyer, M.; Etchegoin, P. G. J. Phys. Chem. C 2007, 111, 13794-13803. doi:10.1021/jp0687908

\section{License and Terms}

This is an Open Access article under the terms of the Creative Commons Attribution License

(http://creativecommons.org/licenses/by/4.0). Please note that the reuse, redistribution and reproduction in particular requires that the authors and source are credited.

The license is subject to the Beilstein Journal of Nanotechnology terms and conditions:

(https://www.beilstein-journals.org/bjnano)

The definitive version of this article is the electronic one which can be found at:

doi:10.3762/bjnano.10.105 